\title{
DIAMOND DISSOLUTION IN KIMBERLITE AND LAMPROITE MELTS AT DEEP CRUSTAL CONDITIONS
}

\author{
Yusuke Kozai and Makoto Arima \\ Geological Institute, Yokohama National University, Japan
}

\section{INTRODUCTION}

Crystal form of natural diamond reflects environmental conditions under which it grew and/or dissolved (Sunagawa, 1984; Arima, 1996). Natural diamond crystals hosted by kimberlite or lamproite commonly display variety of crystal forms, ranging from octahedral or cubic forms to tetrahexahedroidal, dodecahedroidal, and ball-like forms (Sunagawa, 1984; Robinson et al., 1989). The octahedral and cubic forms are considered to be primary growth habit of diamond and the other crystal forms have been largely attributed to result of diamond dissolution into the host magma during its ascent (Sunagawa, 1984; Robinson et al., 1989).

Dissolution of diamond into the host magma likely depends on temperature, pressure, redox state and chemical composition of the host magma. Exposed time of diamond to the host magma is an additional factor determining degree of diamond dissolution (Arima, 1996). To evaluate diamond dissolution processes into kimberlite and lamproite melts under various conditions, we carried out a series of diamond dissolution experiments in the graphite stability field $\left(1300-1500^{\circ} \mathrm{C}\right.$ and 1.0 to $2.5 \mathrm{GPa}$ ) and determined dissolution rate of diamond crystal into kimberlitic and lamproitic melts. Kimberlite used is a natural group 1 kimberlite sample from Wesselton Mine, South Africa (Edgar et al., 1988), which contains 25.6 wt. $\% \mathrm{SiO}_{2}, 3.4$ wt. $\% \mathrm{Al}_{2} \mathrm{O}_{3}, 3.3$ wt. $\% \mathrm{TiO}_{2}, 10.3$ wt. $\% \mathrm{Fe}_{2} \mathrm{O}_{3}{ }^{\mathrm{T}}, 0.2$ wt.\% $\mathrm{MnO}, 27.2$ wt.\% $\mathrm{MgO}, 15.3$ wt.\% $\mathrm{CaO}, 0.3$ wt.\% $\mathrm{Na}_{2} \mathrm{O}, 0.7$ wt.\% $\mathrm{K}_{2} \mathrm{O}, 1.8$ wt. $\% \mathrm{P}_{2} \mathrm{O} 5,4.8$ wt. $\% \mathrm{CO}_{2}$ and 6.2 wt. $\% \mathrm{H}_{2} \mathrm{O}$. The lamproite used is a phlogopite lamproite sample from Mount North, West Kimberley, Australia, which contains 48.4 wt.\% $\mathrm{SiO}_{2}, 6.9$ wt.\% $\mathrm{Al}_{2} \mathrm{O}_{3}, 5.8$ wt.\% $\mathrm{TiO}_{2}, 5.5$ wt.\% $\mathrm{Fe}_{2} \mathrm{O}_{3}, 1.6$ wt.\% $\mathrm{FeO}, 0.1$ wt.\% $\mathrm{MnO}$, 11.5 wt.\% $\mathrm{MgO}, 4.4$ wt.\% $\mathrm{CaO}, 0.7$ wt.\% $\mathrm{Na}_{2} \mathrm{O} 8.0$ wt. $\% \mathrm{~K}_{2} \mathrm{O}, 1.0$ wt. $\% \mathrm{P}_{2} \mathrm{O}_{5}, 1.0$ wt. $\% \mathrm{BaO}, 0.4$ wt. $\% \mathrm{CO}_{2}$ and 2.8 wt. $\% \mathrm{H}_{2} \mathrm{O}$. To examine the role of $\mathrm{CO}_{2}$ in silicate melts in diamond dissolution processes, several kimberlite compositions with various $\mathrm{CaMg}\left(\mathrm{CO}_{3}\right)_{2}$ content were prepared.
Natural octahedral diamond crystals from Siberia $(0.8$ to $1 \mathrm{~mm}$ in diameter) were used as the starting crystal. The crystals are inclusion-free octahedron with pointed corners, sharp edges and flat $\{111\}$ faces. A diamond crystal and the kimberlite or lamproite powder were placed in a sealed inner Pt capsule (4 $\mathrm{mm}$ in diameter). The inner capsule was then loaded with W-I buffer powder in a sealed outer Pt capsule (6 $\mathrm{mm}$ in diameter). Experiments were carried out with a piston cylinder high-pressure apparatus with 34-mm bore diameter. We first increased pressure, then temperature was increased after pressure reached to the run condition. Temperature was measured with a Pt-Pt13\%Rh thermocouple. After run, the sample was quenched under the run pressure by cutting off the heating electric power. It took about 30 sec to reach from $1300^{\circ} \mathrm{C}$ to $100^{\circ} \mathrm{C}$. After experiments, we measured weight of the diamond crystal to evaluate weight change due to dissolution. We examined morphology of the diamond crystal with a differential interference microscope and SEM.

In the experiments with the Wesselton kimberlite composition, kimberlite portions of the run-products are composed of dendritic quench-crystal aggregates with minor amounts of euhedral olivine and spinel crystals. In the experiments with the Mount North lamproite composition, lamproite portions of the run products are entirely composed of dendritic quench crystal aggregate. No graphite was present in all the run products. To examine the effect of carbon (or $\mathrm{CO}_{2}$ ) concentration in a dissolution agent on the diamond dissolution, we prepared several kimberlite compositions with various amounts of $\mathrm{CaMg}\left(\mathrm{CO}_{3}\right)_{2}$.

\section{DISSOLUTION AND DIAMOND MORPHOLOGY}

All diamonds in the run products at $1300^{\circ} \mathrm{C}$ and 1.0 $\mathrm{GPa}$ exhibited preferential resorption of corners and edges of the starting diamond crystal as dissolution proceeded. In runs with the Wesselton kimberlite composition, we observed extensive degree of dissolution. In these runs, curved faces truncated the $\{111\}$ faces of the starting diamond crystal and no $\{111\}$ face was preserved after 180 min run duration. Morphology of the diamond crystal changed from an 


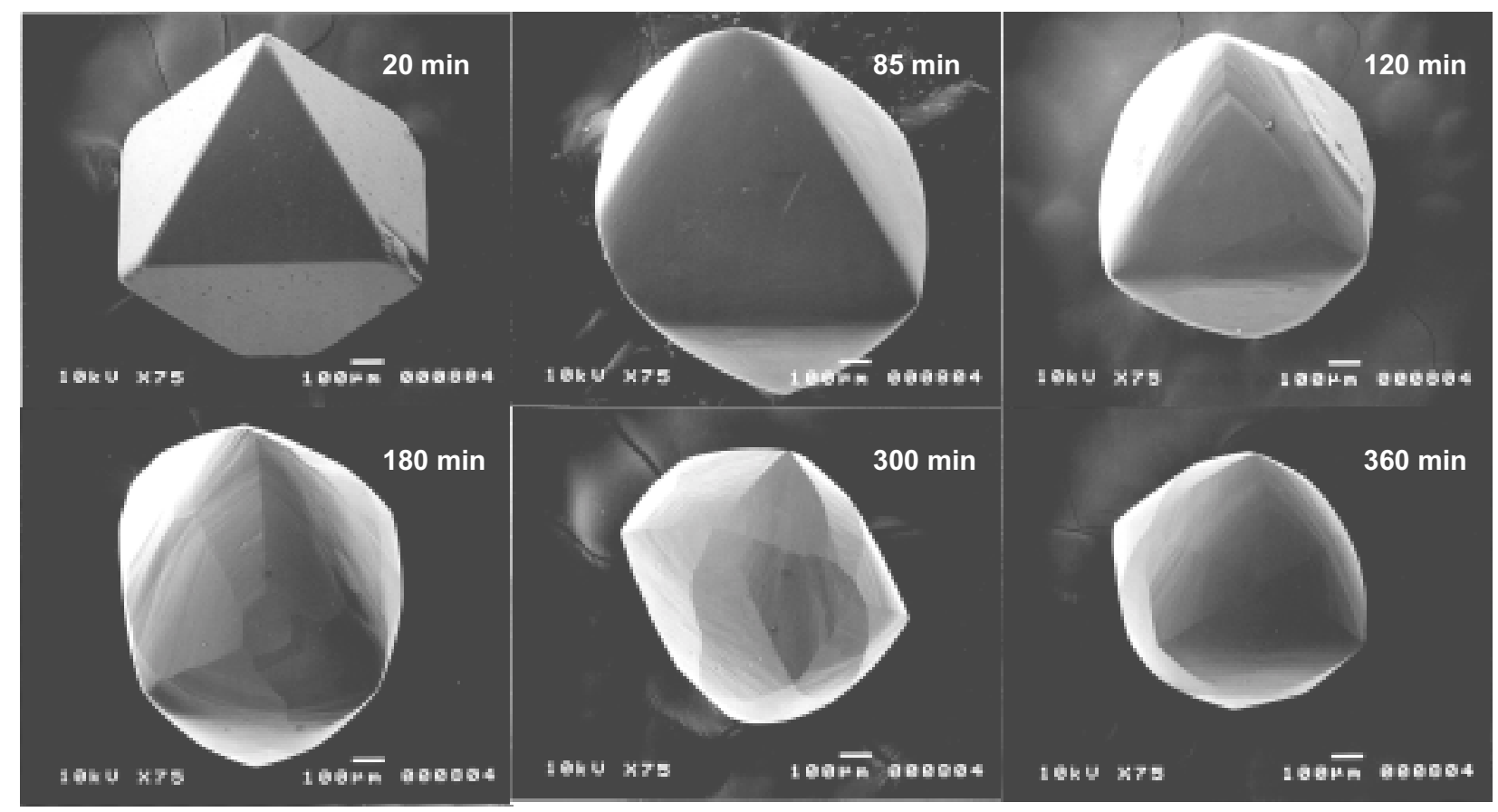

Figure 1: Morphological changes of octahedral diamond by dissolution process in kimberlite melt at $1300^{\circ} \mathrm{C}$ and $1.0 \mathrm{GPa}$.

original octahedral form through a hexoctahedral form to a tetrahexahedroidal and finally transformed to a dodecahedroidal form as dissolution proceeded (Fig. 1). Numbers of small trigons were developed on the $\{111\}$ face. The size of trigon clearly increases with run duration. The trigons are negatively oriented to the original triangular $\{111\}$ faces of the host diamond. With increasing run duration, the trigons changed from smaller and shallower flat-bottomed type to larger and deeper point-bottomed type.

Comparing with the runs with the kimberlite composition, diamond crystals in the runs with the Mount North lamproite composition showed lower degree of dissolution. Starting from an octahedral crystal form with pointed corners, sharp edges and flat faces, the diamond crystals became more rounded but still exhibited the original octahedral habit. For instance, the diamond crystal in the run with $550 \mathrm{~min}$ run duration showed rounded corners and edges together with shallow flat-bottomed etch pits on the $\{111\}$ faces but its original octahedral form was well preserved. No deep point-bottomed trigon was observed in these runs.

\section{DIAMOND DISSOLUTION RATE}

As dissolution proceeded, the diamond crystal became more rounded form with rounded edges and curved faces and finally transformed to more spherical forms. In order to evaluate dissolution rate $(\mathrm{mm} / \mathrm{hr})$, we approximate dissolved crystal forms as a sphere and converted the observed weight change of the starting crystal to the volume change, using the density of diamond $(3.52 \mathrm{~g} / \mathrm{cm} 3)$. Calculated radius change of the modeled sphere crystal increases linearly with run duration.

The present data indicate that the diamond dissolution rate at $1300^{\circ} \mathrm{C}$ and $1.0 \mathrm{GPa}$ is $0.014 \mathrm{~mm} / \mathrm{hr}$ into the Wesselton kimberlite melt and $0.0026 \mathrm{~mm} / \mathrm{hr}$ into the Mount North lamproite melt (Fig. 2-a). Degree of diamond dissolution highly depends on run temperature, run duration, and composition of dissolution agent. The data suggest that higher temperature in the host magma lead to higher degree of diamond dissolution. Arima (1996) reported diamond dissolution experiments at $1300-1500^{\circ} \mathrm{C}$ and $2.5 \mathrm{GPa}$. The data (Arima, unpublished) indicate that the diamond dissolution rates into the synthetic kimberlite composition are 0.026 $\mathrm{mm} / \mathrm{hr}$ at $1500^{\circ} \mathrm{C}$ and $2.5 \mathrm{GPa}$ and $0.007 \mathrm{~mm} / \mathrm{hr}$ at $1300^{\circ} \mathrm{C}$ and $2.5 \mathrm{GPa}$ (Fig. 2-b)

Arima (1996) suggested that lower $\mathrm{CO}_{2}$ concentration of the host kimberlitic melt result in higher degree of diamond dissolution. To examine the effect of $\mathrm{CO}_{2}$, 


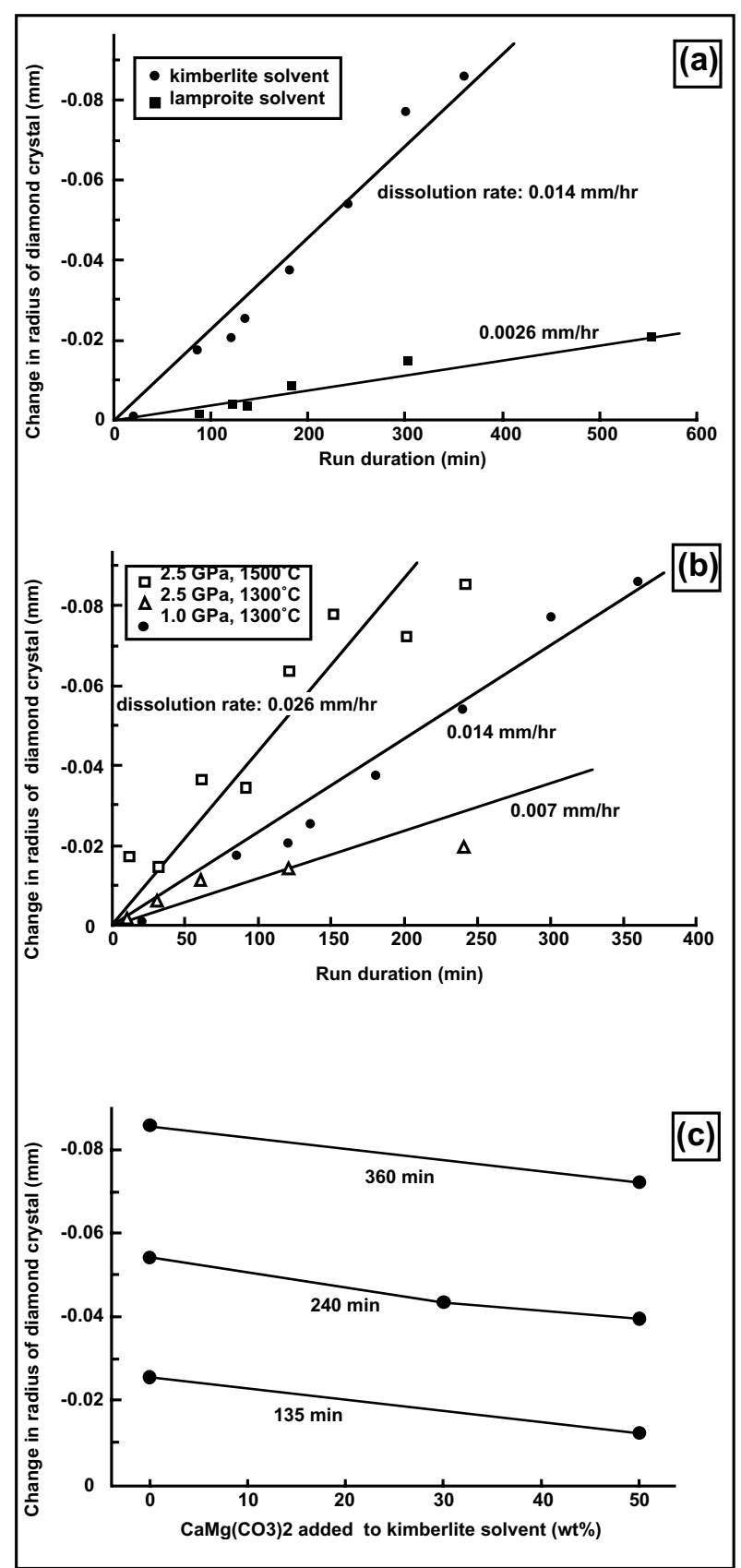

Figure 2: Experimental results of diamond dissolution. (a) Dissolution rate of diamond in kimberlitic and lamproitic melts at $1.0 \mathrm{GPa}, 1300^{\circ} \mathrm{C}$. (b) Dissolution rate of diamond in kimberlitic melt at different pressures and temperatures. (c) Diamond dissolution in kimberlite - $\mathrm{CaMg}\left(\mathrm{CO}_{3}\right)_{2}$ system at $1.0 \mathrm{GPa}, 1300^{\circ} \mathrm{C}$.

$\mathrm{CaMg}\left(\mathrm{CO}_{3}\right)_{2}$ was added to the Wesselton kimberlite composition. The run results indicate that addition of carbonate to the kimberlite composition suppresses degree of diamond dissolution (Fig. 2-c). In addition, no diamond dissolution was noted in the run in the system diamond- $\mathrm{CaMg}\left(\mathrm{CO}_{3}\right)_{2}$ at $1300^{\circ} \mathrm{C}$ and $1.0 \mathrm{GPa}$.
It is likely that diamond dissolves into silicate melts as $\mathrm{CO}_{2}$ by an oxidizing reaction.

At the same P-T condition $\left(1.0 \mathrm{GPa}, 1300^{\circ} \mathrm{C}\right)$, the diamond dissolution rate into the Wesselton kimberlite melt is $0.014 \mathrm{~mm} / \mathrm{hr}$, five times higher than the rate into the Mount North lamproite melt $(0.0026 \mathrm{~mm} / \mathrm{hr})$. The present result is rather difficult to interpret as the kimberlite contains higher $\mathrm{CO}_{2}$ than the lamproite. Arima (1996) discussed that degree of diamond dissolution into silicate melt likely depends on redox state and activities of ferric and ferrous iron in the melt. Higher diamond dissolution rate into the kimberlite is probably due to highly oxidized state of the former composition.

Diamond dissolution is thought to occur within transporting kimberlite magma (Robinson et al., 1989). The present experimental results clearly demonstrate that diamond dissolves into kimberlite and lamproite melts in the graphite stability field. The morphological features observed are comparable to those reported from natural diamonds (Sunagawa, 1984; Robinson et al., 1989). The results suggest that dissolution processes of diamond into silicate magmas highly depend on temperature, time, carbon concentration and redox state of magma. Higher temperature, higher oxidation state, and lower $\mathrm{CO}_{2}$ concentration of host magma resulted in higher degree of diamond dissolution.

\section{REFERENCES}

Arima, M., 1996. Experimental study of growth and resorption of diamond in kimberlitic melts at high pressures and temperatures. Proc. $3^{\text {rd }}$ NIRIM Intern. Symp. Advanced Materials, pp. 223-228.

Edgar, A.D., Arima, M., Baldwin, D.K., Bell, D.R, Shee, S.R., Skinner, E.M.W., Walker, E.C., 1988. High-pressurehigh-temperature melting experiments on a $\mathrm{SiO}_{2}$-poor aphanitic kimberlite from the Wesselton Mine, Kimberley, South Africa. American Mineralogist, 73, pp. 524-533.

Robinson, D.N., Scott, J.A., Van Niekerk, A., Anderson, V.G., 1989. The sequence of events reflected in the diamonds of some southern African kimberlites. In: Ross, J., Jaques, A.L., Ferguson, J., Green, D.H., O'Reilly, S.Y., Danchin, R.V. and Janes, A.J.A. (Eds.), Kimberlite and Related Rocks, v. 2. GSA Special Publication, No. 14, Blackwell, Carlton, pp. 990-1000.

Sunagawa, I., 1984. Morphology of natural and synthetic diamond crystals. In: Sunagawa, I. (Ed.), Material 
Science of the Earth's Interior: Tokyo, Terra Scientific, pp. 303-330.

Contact: Y. Kozai, C/o Prof. M. Arima, Geological Institute, Yokohama National University, 79-7 Tokiwadai, Hodogaya-

ku, Yokohama 240-8501, Japan. E-mail: d02ta003@ynu.ac.jp 